\title{
Gut region-specific accumulation of reactive oxygen species leads to regionally distinct activation of antioxidant and apoptotic marker molecules in rats with STZ-induced diabetes
}

\author{
Zsanett Jancsó ${ }^{\mathrm{a}}$, Nikolett Bódi ${ }^{\mathrm{b}}$, Barbara Borsos ${ }^{\mathrm{a}}$, Éva Fekete ${ }^{\mathrm{b}}$, Edit Hermesz ${ }^{\mathrm{a}, *}$ \\ a Department of Biochemistry and Molecular Biology, Faculty of Science and Informatics, University of Szeged, Szeged, Hungary \\ ${ }^{\mathrm{b}}$ Department of Physiology, Anatomy and Neuroscience, Faculty of Science and Informatics, University of Szeged, Szeged, Hungary
}

\section{A R T I C L E I N F O}

\section{Article history:}

Received 19 December 2014

Received in revised form 3 March 2015

Accepted 9 March 2015

Available online 18 March 2015

\section{Keywords:}

Apoptosis

Diabetes

Digestive tract

Peroxynitrite

Necrosis

\begin{abstract}
A B S T R A C T
The aim of this study was to seek possible links between the regionality along the digestive tract and the accumulation of reactive oxygen species, the effectiveness of the antioxidant defense system and the sensitivity to the types of demise in different gut regions of rats with streptozotocin-induced diabetes. Significant changes were observed in the oxidative status and in the activity of the antioxidant defense system in the diabetic colon; the peroxynitrite production was doubled, the level of hemoxygenase2 protein was increased 11 -fold and the expression of anti-apoptotic $b c l-2$ was also increased. The segment-specific vulnerability of the gastrointestinal tract induced by hyperglycemia was also confirmed by electron microscopy, demonstrating the presence of severe necrosis in the colon of the diabetic rats. No remarkable histopathological alterations were seen in the duodenum of the diabetic animals and there were likewise no significant changes in the production of peroxynitrite in their duodenum, whereas the level of the free radical scavenger metallothionein- 2 was increased $\sim 300$-fold.

Conclusion: The spatially restricted vulnerability observed along the digestive tract could originate from a high level of oxidative stress via peroxynitrite production.
\end{abstract}

(c) 2015 Elsevier Ltd. All rights reserved.

\section{Introduction}

Type 1 diabetes mellitus (T1D) results in severe metabolic imbalances and pathological changes in many tissues, and commonly affects the entire gastrointestinal (GI) tract, from the esophagus to the anorectal region (Wolosin and Edelman, 2000; Zhao et al., 2002). T1D involves a state of high oxidative stress generated as a result of hyperglycemia-induced reactive oxygen species (ROS) (Wolff, 1993). Oxidative stress is an imbalance between the production of ROS, and the ability of a biological system to achieve the ready detoxification of ROS or to repair the resulting damage. While ROS are important second messengers at low concentrations and are involved in the regulation of apoptosis and the activation of transcription factors, they can cause significant cellular damage when present in excess. They can inflict damage on all classes of cellular macromolecular components,

\footnotetext{
* Corresponding author at: Department of Biochemistry and Molecular Biology, Faculty of Science and Informatics, University of Szeged, P.O. Box 533, H-6701 Szeged, Hungary. Tel.: +36 62 544887; fax: +36 62544887.

E-mail address: hermesz@bio.u-szeged.hu (E. Hermesz).
}

eventually leading to tissue injury or even cell death, which can occur essentially by two mechanisms, necrosis and apoptosis (Bergamini et al., 2004). Although numerous reports have provided details of the molecular mechanisms responsible for ROSinduced apoptosis, little is known concerning the mechanisms and signal transduction pathways underlying ROS-mediated necrotic cell death. Necrosis has long been considered to be a passive mode of cell death (Kanduc et al., 2002) and much more harmful than apoptosis because it causes a robust inflammatory response (Proskuryakov et al., 2003).

To eliminate the harmful effects of reactive species, cells are equipped with an efficient antioxidant defense system, including enzymes such as superoxide dismutase (SOD), catalase (CAT), and heme oxygenases (HOs), and low-molecular weight antioxidants such as glutathione (GSH) and metallothioneins (MTs) (Kruidenier et al., 2003; Inoue et al., 2008). SOD catalyzes the reduction of the superoxide anion $\left(\bullet^{\circ} \mathrm{O}_{2}^{-}\right)$to hydrogen peroxide $\left(\mathrm{H}_{2} \mathrm{O}_{2}\right)$, which is then detoxified to water by CAT in the lysosomes (Wang and Ballatori, 1998). The HOs play roles in heme degradation, yielding equimolar amounts of biliverdin, and carbon monoxide with important free radical-scavenging properties and free iron. HO-2 is expressed constitutively, contributing to cell homeostasis, whereas 
HO-1 is an inducible enzyme expressed at a relatively low level in most tissues (Maines, 1997), recently identified as an important cellular defense mechanism against oxidative stress (Abraham et al., 2009). HO-1 and HO-2 are regulated by strikingly different mechanisms, which may reflect different physiological and pathological roles (Gibbons and Farrugia, 2004).

GSH also plays a critical role in this system, as an antioxidant, enzyme cofactor and major redox buffer (Wang and Ballatori, 1998). The MTs are present in all cells throughout the body. They have a cardinal role in metal homeostasis and heavy metal detoxification through their high metal-binding capacity, they play a role in the immune function, and they are involved in a variety of GI tract functions (Thirumoorthy et al., 2011). They also play an important part in the prevention of development of T1D, the complications and the subsequent pathogenic toxicity (Cai, 2004). The overexpression of MTs in various metabolic organs has been shown to reduce hyperglycemia-induced oxidative stress, organ-specific diabetic complications, and DNA damage in experimental diabetes (Islam and Loots, 2007).

In an earlier study, we demonstrated spatially-restricted damage of the gut capillary endothelium in rats with streptozotocin (STZ)-induced diabetes in comparison with control animals (Bódi et al., 2012). Metagenomic analysis of the luminal contents of duodenum, ileum and colon of diabetic rats also furnishes evidence of the regionality of the gut microbiota (Wirth et al., 2014). The two studies are in good agreement as concerns the advantageous status of the duodenum of the diabetic rat as compared with the colon.

Those results led us to focus in the present study on the spatiallyrestricted differences in ROS production and activation of the antioxidant defense system in the duodenum and colon of rats with STZ-induced diabetes. The aim of the study was to characterize the possible links between the antioxidant status and the macromolecular damage in selected gut segments in the diabetic rat. We report data on the accumulation of a powerful oxidant, peroxynitrite $\left(\mathrm{ONOO}^{-}\right)$, the activities of antioxidant enzymes (SOD and CAT), and the expressions of a set of genes coding for members of antioxidant defense system ( $m t-1, m t-2, h o-1$ and $h o-2)$, together with the detection of pro-apoptotic and anti-apoptotic markers (bax, bcl-2 and caspase-9).

\section{Materials and methods}

\subsection{Animal model}

Adult male Wistar rats weighing 300-400 g, kept on standard laboratory chow (Bioplan Kft., Hungary) and with free access to drinking water, were used throughout the experiments. The rats were divided randomly into three groups: STZ-induced diabetics ( $n=14)$, insulin-treated diabetics $(n=12)$ and sex- and age-matched controls $(n=6)$.

Hyperglycemia was induced as described previously (Izbéki et al., 2008). The animals were considered diabetic if the nonfasting blood glucose concentration was higher than $18 \mathrm{mM}$. From this time on, one group of hyperglycemic rats received a subcutaneous injection of insulin (Humulin M3, Eli Lilly Nederland) each morning ( $4 \mathrm{U}$ ) and afternoon ( $2 \mathrm{U}$ ). The non-fasting blood glucose concentration and weight of each animal were measured weekly. The cecum size of the sacrificed rat was analyzed by means of the Image J $1.48 \mathrm{v}$ program (http://imagej.nih.gov/ij/). In all procedures involving experimental animals, the principles of laboratory animal care (NIH publication no. 85-23, revised 1985) were followed and all the experiments received approval in advance from the Local Ethics Committee for Animal Research Studies at the University of Szeged.

\subsection{Tissue handling}

Ten weeks after the onset of diabetes, the animals were killed by cervical dislocation under chloral hydrate anesthesia $(375 \mathrm{mg} / \mathrm{kg}$ i.p.). The gut segments of the control, STZ-induced diabetic and insulin-treated diabetic rats were dissected and rinsed in $0.05 \mathrm{M}$ phosphate buffer, pH 7.4. Samples were taken from the duodenum ( $1 \mathrm{~cm}$ distal to the pylorus) and the middle part of the colon and processed for biochemical, molecular biological and electron microscopy study.

\subsection{Biochemical assays}

$0.5 \mathrm{~g}$ duodenum and colon of each individual rats, tissues were homogenized in 4 volume of ice-cold $0.9 \%$ serum physiologic by means of a glass homogenizer immersed in an ice water bath, centrifuged at $17,000 \times g$ for $15 \mathrm{~min}$ at $4{ }^{\circ} \mathrm{C}$, and the clear supernatants used for $\mathrm{GSH}, \mathrm{ONOO}^{-}$, protein analysis, and measuring the activities of antioxidant enzymes.

Total protein levels measured by the method of Lowry et al. (1951) using bovine serum albumin as a standard. The concentrations of total and reduced GSH in the tissues were measured as described by Sedlak and Lindsay (1968). Spectrophotometric measurements were carried out by GENESYS 10S UV-Vis (Thermo Scientific) spectrophotometer.

$\mathrm{ONOO}^{-}$was assayed by diluting samples into $1 \mathrm{M} \mathrm{NaOH}(60: 1)$ and measuring the increase in absorbance at $302 \mathrm{~nm}$. As a control, samples were added to $100 \mathrm{mM}$ potassium phosphate ( $\mathrm{pH} 7.4)$ (60:1). The decrease in absorbance was measured at neutral $\mathrm{pH}$ as $\mathrm{ONOO}^{-}$decomposes (Huie and Padmaja, 1993).

Catalase activity was determined spectrophotometrically at $240 \mathrm{~nm}$ by the method of Beers and Sizer (1953) and expressed in Bergmeyer units ( $1 \mathrm{BU}=$ decomposition of $1 \mathrm{~g} \mathrm{H}_{2} \mathrm{O}_{2} / \mathrm{min}$ at $25^{\circ} \mathrm{C}$ ).

SOD activity was determined on the basis of the inhibition of epinephrine-adrenochrome autoxidation (Misra and Fridovich, 1972). Spectrophotometric measurement was carried out at $480 \mathrm{~nm}$. The results were expressed in $\mathrm{U} / \mathrm{mg}$ protein.

\subsection{Post-embedding immunohistochemistry}

For post-embedding immuno-electromicroscopy, small pieces $(2-3 \mathrm{~mm})$ of the gut segments were fixed overnight at $4{ }^{\circ} \mathrm{C}$ in $2 \%$ paraformaldehyde and $2 \%$ glutaraldehyde solution, buffered with $0.1 \mathrm{M}$ PB (pH 7.4). The samples were then washed in $0.05 \mathrm{M} \mathrm{PB}$ and further fixed for $1 \mathrm{~h}$ in $1 \% \mathrm{OsO}_{4}$. After fixation, the gut segments were rinsed in $0.1 \mathrm{M} \mathrm{PB}$, dehydrated in increasing alcohol concentrations (50,70,96\% and absolute ethanol) and acetone, and embedded in Epon (Electron Microscopy Sciences, Hatfield, PA, USA). The Epon blocks were used to prepare ultrathin $(70 \mathrm{~nm}) \mathrm{sec}$ tions, which were mounted on Formvar-coated nickel grids and processed for immunogold labeling.

Ultrathin sections from each block were pre-incubated in $1 \%$ bovine serum albumin in TRIS-buffered saline (TBS) for $30 \mathrm{~min}$, incubated overnight in the primary antibodies (heme oxygenase- 2 mouse monoclonal IgG (Santa Cruz Biotechnology, USA; working dilution 1:50) and caspase-9 rabbit polyclonal IgG (Sigma-Aldrich, USA; working dilution 1:50)), followed by protein A-gold-conjugated anti-mouse (18 nm gold particles, Jackson ImmunoResearch, West Grove, PA, USA; final dilution 1:20) secondary antibodies for $3 \mathrm{~h}$, with extensive washing in between. All steps were performed at room temperature. The specificity of the immunoreaction was assessed in all cases by omitting the primary antibodies from the labeling protocol and incubating the sections only in the protein A-gold-conjugated secondary antibodies. Sections were counterstained with uranyl acetate (Merck, Darmstadt, Germany) and lead citrate (Merck, Darmstadt, Germany), and were 
examined and photographed with a Philips CM 10 electron microscope equipped with a MEGAVIEW II camera. The quantitative properties of gold particles coding for HO-2 and caspase- 9 were determined in the myenteric ganglia and in the endothelium of capillaries in the vicinity of these ganglia in all experimental group. Counting was performed on digital photographs of five ganglia, and the entire endothelial profile of five well-oriented capillaries, which were cut perpendicularly to their long axis and visualized at a magnification of $5800 \times$, per intestinal segment per condition at a magnification of $34,000 \times$ with the AnalySIS 3.2 program (Soft Imaging System GmbH, Münster, Germany). The intensity of the labeling was expressed as the total number of gold particles per unit area.

\subsection{RNA extraction, reverse transcription and PCR amplification}

Intestinal samples were homogenized in RNA Bee reagent (TelTest Inc., Friendswood, TX, USA) and total RNA was prepared according to the procedure suggested by the manufacturer. Total RNA was routinely treated with 100 U RNAse-free DNAseI (Thermo Scientific) to avoid any DNA contamination. For assessing RNA concentration and purity the absorbance of a diluted RNA samples were measured at 260 and $280 \mathrm{~nm}$ using NanoDrop 1000 UV/VIS Spectrophotometer (Thermo Scientific). The RNA concentration was calculated using the $A_{260}=1.0$ is equivalent to $\sim 40 \mu \mathrm{g} / \mathrm{ml}$ singlestranded RNA equation. The $A_{260} / A_{280}$ ratio was used to assess RNA purity and ratio $\sim 2$ was accepted for purified RNA.

First-strand cDNA was synthesized by using $3 \mu \mathrm{g}$ total RNA as template, $200 \mathrm{pmol}$ of each dNTP (Thermo Scientific), $200 \mathrm{U}$ Maxima H Minus Reverse Transcriptase (Thermo Scientific) and $500 \mathrm{pmol}$ random hexamer primers (Sigma) in a final volume of $20 \mu \mathrm{L}$, and incubated for $10 \mathrm{~min}$ at $37^{\circ} \mathrm{C}$, followed by $1 \mathrm{~h}$ at $52^{\circ} \mathrm{C}$. Real-time qPCR was done for gene expression studies, using Luminaris Color HiGreen Low ROX qPCR Master Mix (Thermo Scientific) in Applied Biosystems 7500 Real-Time PCR System (Life Technologies). The qPCR reactions were performed with a temperature program of $10 \mathrm{~min}$ at $95^{\circ} \mathrm{C}$ (initial denaturing), followed by 40 cycles of $15 \mathrm{~s}$ at $95^{\circ} \mathrm{C} ; 1 \mathrm{~min}$ at the annealing temperature $63^{\circ} \mathrm{C}$ followed by a melting curve stage with temperature ramping from 60 to $95^{\circ} \mathrm{C}$ and a final cooling for $30 \mathrm{~s}$ at $40^{\circ} \mathrm{C}$. The quantities of examined mRNAs were normalized to that of $\beta$-actin, a housekeeping gene, and gene expression was calculated in terms of ddCt method (Livak and Schmittgen, 2001).

Table 1

Primer sequences with accession number.

\begin{tabular}{ll}
\hline Gene & Primers $\left(5^{\prime} \rightarrow 3^{\prime}\right)$ \\
\hline ho-1 (NM_012580) & GCTGCTGGTGGCCCACGCTT \\
ho-2 (NM_024387) & ACAGTCCAATGTTGAGCAGG \\
& GCTGCTGGTGGCCCACGCTT \\
$m t-1$ (M11794) & AGGGTTCTTTGTTAGCATGGA \\
mt-2 (AY341880) & ATGGACCCCAACTGCTCCTG \\
Caspase-9 (NM_031632) & TGGAGGTGTACGGCAAGACT \\
bax (RRU49729) & ATGGACCCCAACTGCTCCTG \\
bcl-2 (NM_016993) & GAAAAAGTGTGGAGAACCG \\
& AGCCAGATGCTGTCCCATAC \\
& CAGGAACCGCTCTTCTTGTC \\
& GGAGGCGGCGGGCCCACCAG \\
& CACGTCAGCAATCATCCTCTGC \\
& GGAAGGATGGCGCAAGCCGG \\
& CGCAGGCCCAGCGTTGGCGAC \\
& GCAAGAGAGGTATCCTGACC \\
\end{tabular}

For the amplification of rat mRNAs, isoform-specific primers were designed on the basis of the data bank entries. For normalization of the amounts of $m t$, ho, caspase-9, bax and bcl-2 mRNAs, the $\beta$-actin mRNA level was used as internal standard (Table 1).

\subsection{Statistical analysis}

RT-qPCR reactions for each animal were performed in triplicate to increase the reliability of the measurements. Statistical analysis was performed with one-way ANOVA and the Newman-Keuls test. All analyses were carried out with GraphPad Prism 4.0 (GraphPad Software, La Jolla, CA, USA) and MedCalc Statistical Software version 9.4.2.0 (MedCalc Software, Mariakerke, Belgium). A probability level of $p<0.05$ was set as the level of statistical significance. All data were expressed as means \pm SD.

\section{Results}

3.1. Ischemic and inflammatory hallmarks and peroxynitrite level in different gut segments 10 weeks after the onset of diabetes

Rats were sacrificed and signs of intestinal inflammation and severe ischemia (bluish-purple intestines and an enlarged cecum (1.5-2-fold)) were observed in the diabetic animals as compared with the controls (Fig. 1 A and B). Intestinal ischemia was also visible in the insulin-treated rats, but, the cecum was not enlarged (not shown).

Ten weeks after the onset of diabetes there was no significant change in $\mathrm{ONOO}^{-}$level in the duodenum in any of the examined groups. However, the $\mathrm{ONOO}^{-}$level in the colon was significantly increased (1.7-2-fold) in the diabetic rats, whereas in the insulintreated diabetic animals it was similar to the control level (Fig. 1C).

\subsection{Activation of the antioxidant defense system}

The GSH level in the duodenum was elevated 2.5-3-fold in the diabetic rats and 1.5 -fold in the insulin-treated diabetic rats relative to the control group (Fig. 2A). The elevation in the ratio GSH/GSSG was even higher in this intestinal segment: a 6-fold increase was measured in the diabetic animals (data not shown). In the colon, the GSH and GSSG contents were not significantly changed in any of the experimental groups.

The SOD activity was unaltered in the duodenum, regardless of the treatment, while it was significantly decreased in the colon in the diabetic groups (Fig. 2B). The activity of CAT was not significantly affected by either the STZ-induced diabetes or the insulin replacement in any of the intestinal segments examined (Fig. 2C).

Ten weeks after the STZ injection, there was a 4-fold increase in the expression of the ho-1 gene in the duodenum, but no significant change in the colon. Immediate insulin replacement maintained the mRNA level close to the control value in both intestinal segments (Table 2).

The expression of the $m t-1$ gene was upregulated in both of the examined gut segments of the diabetic animals: the $m t-1 \mathrm{mRNA}$ level was increased by 6 - and 7-fold in the duodenum and the colon, respectively. However, no significant change in $m t-1$ expression was observed in these intestinal segments in the insulin-treated diabetic animals. The $m t-2$ mRNA content was more than 300 -fold the control level in the duodenum of the diabetic animals, while insulin treatment kept the expression level close to the control. The expression of $m t-2$ did not change in the colon in the diabetic and insulin-treated animals (Table 2). 

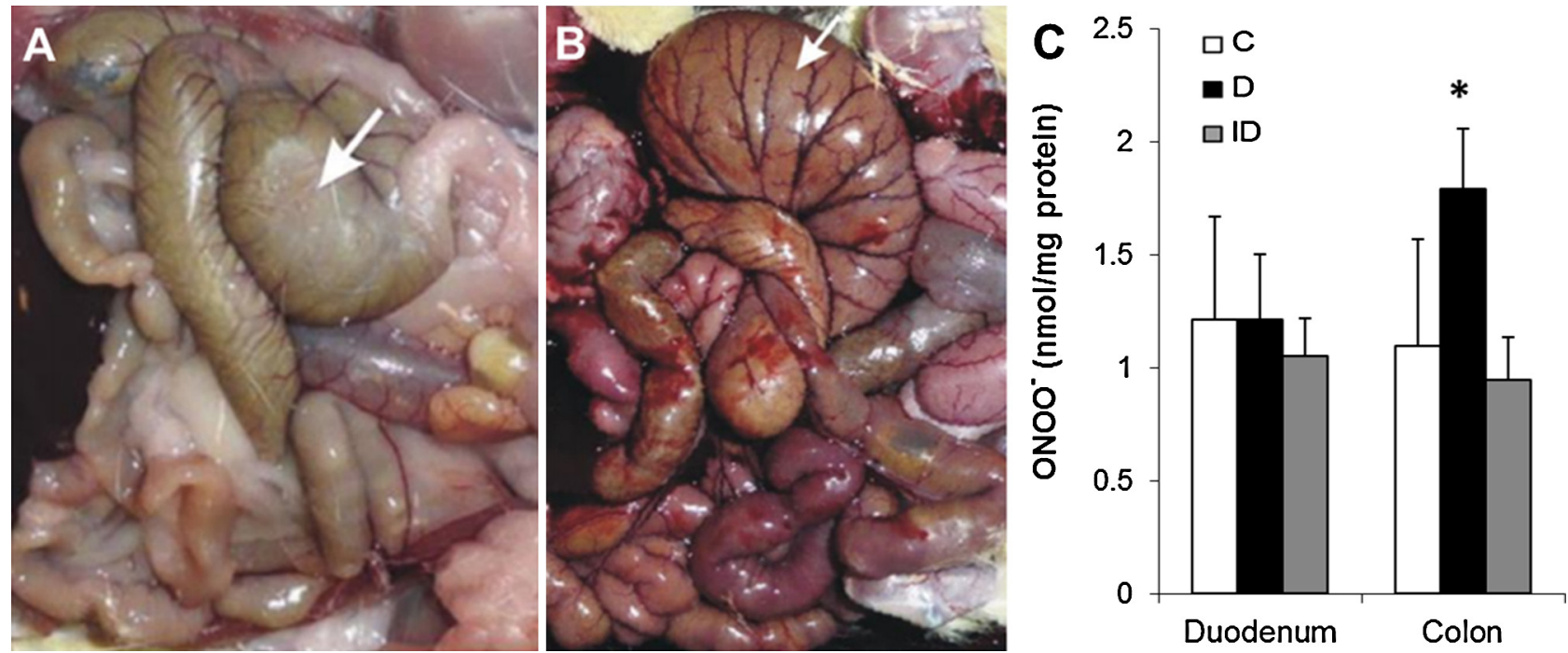

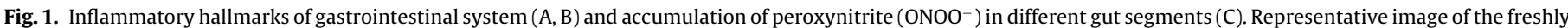

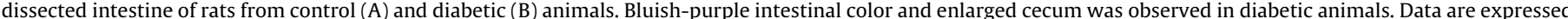
as means \pm S.D. ${ }^{*} p<0.05$ (relative to controls). C: control, $n=6$; D: diabetics, $n=14$; ID: insulin-treated diabetics, $n=12$.
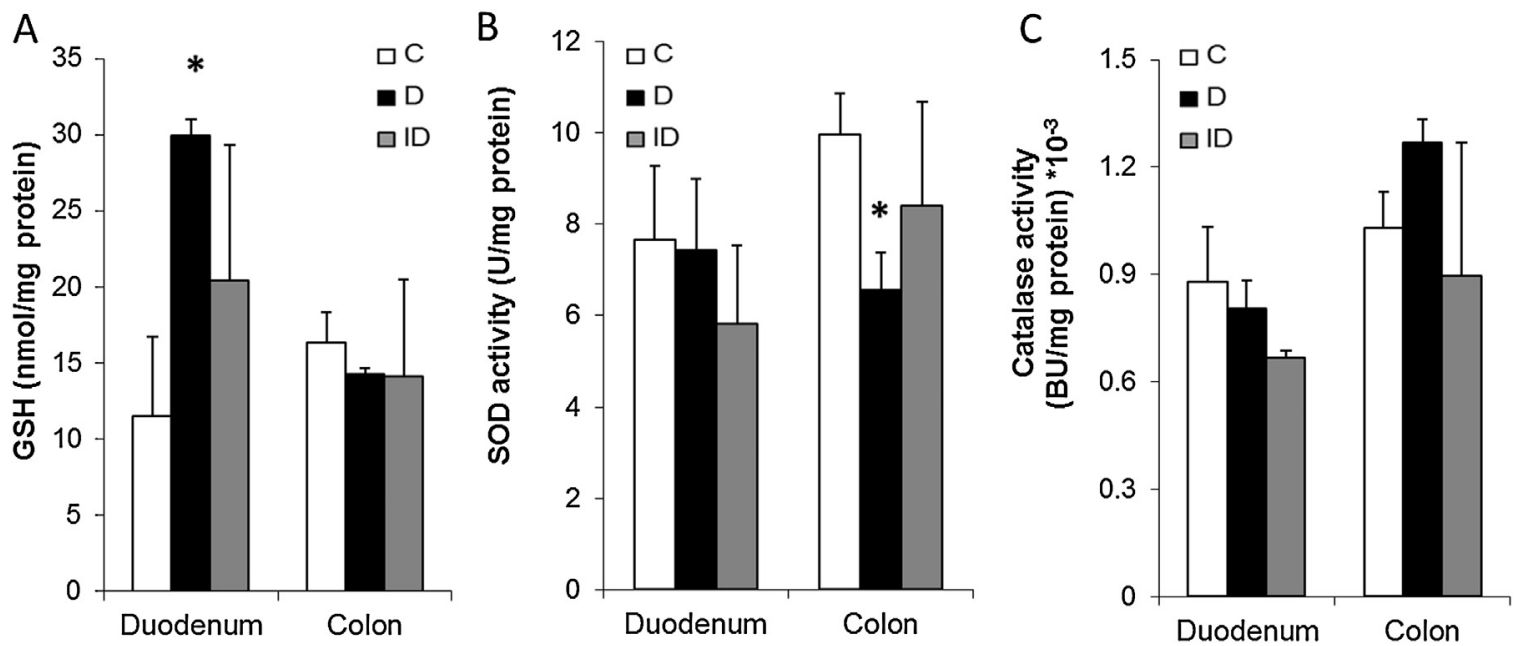

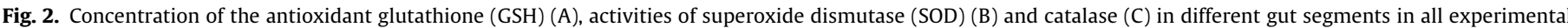
groups. Data are expressed as means \pm S.D. ${ }^{*} p<0.05$ (relative to controls). C: control, $n=6$; D: diabetics, $n=14$; ID: insulin-treated diabetics, $n=12$.

Table 2

Fold of induction of the ho-1, mt-1 and $m t-2$ genes in the duodenum and colon of rats with STZ-induced diabetes.

\begin{tabular}{cllc}
\hline & $h o-1$ & $m t-1$ & $m t-2$ \\
\hline Duodenum & & & \\
C & 1 & 1 & 1 \\
D & $3.93 \pm 1.49^{* * *}$ & $5.94 \pm 2.32^{* * *}$ & $324.74 \pm 167.21^{*}$ \\
ID & $1.28 \pm 0.06^{\ddagger}$ & $1.41 \pm 0.51^{\#}$ & $1.06 \pm 0.01^{\dagger}$ \\
Colon & & & \\
C & 1 & 1 & 1 \\
D & $0.93 \pm 0.06$ & $7.5 \pm 4.95^{*}$ & $1.4 \pm 0.02$ \\
ID & $0.74 \pm 0.19$ & $1.5 \pm 0.99^{\dagger}$ & $1.08 \pm 0.01$ \\
\hline
\end{tabular}

Data are means \pm S.D.

Analysis of variance (ANOVA):

${ }^{*} p<0.05$ (relative to controls)

*** $p<0.001$ (relative to controls).

$\dagger p<0.05$ (relative to diabetic animals).

$\ddagger p<0.01$ (relative to diabetic animals).

\# $p<0.001$ (relative to diabetic animals).

\subsection{Measurement of HO-2 expression in different gut segments}

The expression of the ho- 2 gene was upregulated significantly only in the colon in the diabetic and the insulin-treated diabetic rats (Fig. 3A). The presence of HO-2 protein was followed by post-embedding immunohistochemistry. A $\sim 4$-fold increase was measured in the number of gold particles signing $\mathrm{HO}-2$ in the duodenum of the diabetic animals relative to the controls. In the diabetic colon, there was a marked 11-fold elevation in the HO-2 labels resulting in a $\sim 5$-fold higher protein level of $\mathrm{HO}-2$ in the colon versus duodenum. In both examined regions of the insulin-treated diabetic rats the control level of $\mathrm{HO}-2$ expression was observed (Fig. 3B).

\subsection{Effects of diabetes on apoptotic markers in the duodenum and colon}

We examined the levels of the pro-apoptotic marker bax and the anti-apoptotic marker $b c l-2$. In the duodenum of the diabetic rat, a $40 \%$ increase was detected in the level of bax mRNA as compared 

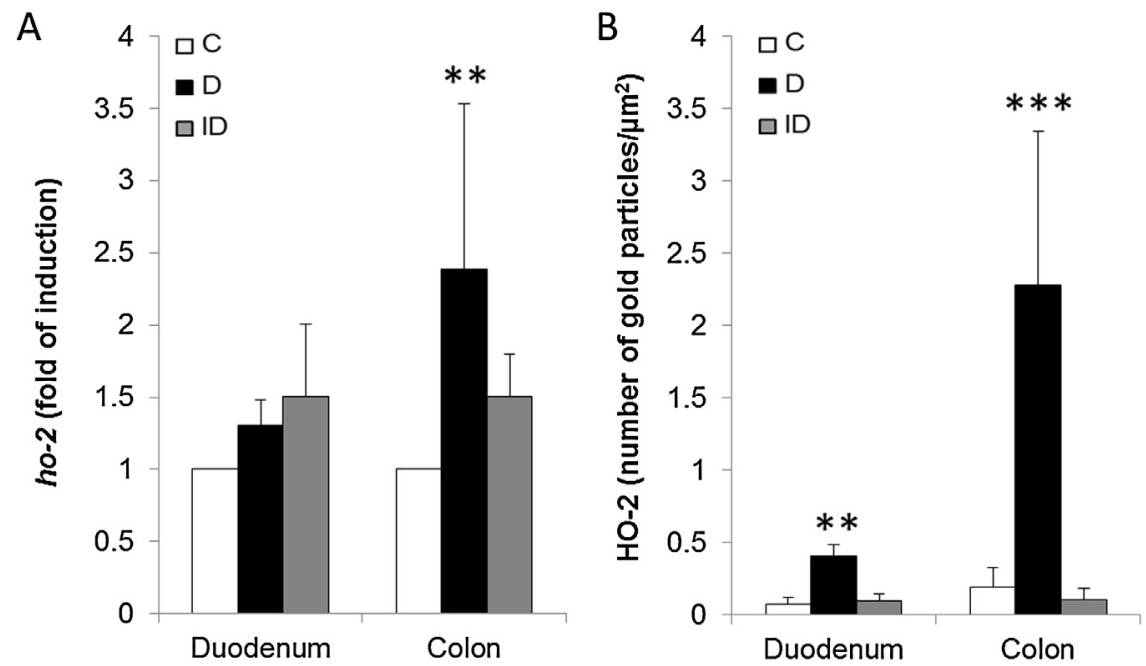

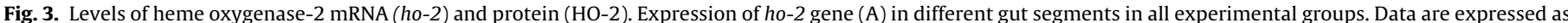

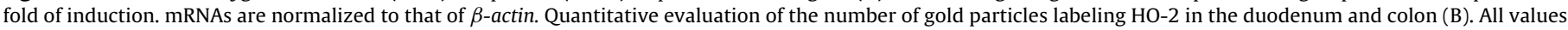
are presented as means \pm S.D. ${ }^{* *} p<0.01,{ }^{* * *} p<0.001$ (relative to controls). C: control, $n=6$; D: diabetics, $n=14$; ID: insulin-treated diabetics, $n=12$.

with the control and insulin-treated groups. However, in the colon of the diabetic rats, the expression of the bax gene was downregulated by $15-20 \%$ (data not shown). The diabetes-induced alterations in the expression of the anti-apoptotic marker blc-2 were the opposite of those in bax expression; no change or a non-significant decrease in the duodenum, and a $40-45 \%$ increase in the colon. As a consequence, the ratio $\mathrm{bax} / \mathrm{bcl}-2$ differed even more dramatically in the two intestinal segments: a 50\% increase in the duodenum, and a $40 \%$ decrease in the colon (Fig. 4A).

The expression pattern of caspase- 9 in the duodenum was similar to that of bax. There was a significant 2.5-3-fold increase in the caspase- 9 mRNA level in the diabetic rats. The expression pattern of this gene was unchanged in the colon in the diabetic animals and the level was the same as the control in the animals treated with insulin (Fig. 4B). The intestinal caspase-9 protein expression was also demonstrated by immunohistochemistry. The number of gold particles labeling caspase- 9 was significantly higher in the duodenum of diabetic rats than the control (Fig. 4C and D), while the number of labels in the colon was unchanged.

The segment-specific vulnerability of the gastrointestinal tract induced by hyperglycemia was also confirmed by electron microscopy, demonstrating the presence of severe necrosis in the colon of the diabetic rats. The hyperglycemic colon samples frequently exhibited necrotic smooth muscle cells with a barely recognizable cytoplasm, and the structural integrity of the plasma membrane was lost (Fig. 5).

\section{Discussion}

This study has presented data on gut segment specific oxidative stress, the effectiveness of the antioxidant defense system and the tissue damage in the duodenum and colon in rats with diabetes.

The segment-specific vulnerability of the GI tract was confirmed by RT-qPCR, immunohistochemistry and electron microscopy (EM). EM demonstrated the presence of severe necrosis in the colon of the diabetic rats. Changes in ROS production, as presumptive candidates triggering necrosis were also demonstrated in the colon: the $\mathrm{ONOO}^{-}$production was doubled. Elevated level of $\mathrm{ONOO}^{-}$serves as indirect evidence of increased ${ }^{\bullet} \mathrm{O}_{2}{ }^{-}$and $\mathrm{NO}$ production in the colon. An increasing number of studies have implicated $\mathrm{ONOO}^{-}$in the development of T1D-associated complications (Pacher et al., 2007). A study of the pathogenesis of inflammatory bowel disease yielded evidence that intrarectally administered $\mathrm{ONOO}^{-}$induced inflammation and transmucosal necrosis in the rat colon (Rachmilewitz et al., 1993). The activity of SOD in the diabetic colon was significantly reduced, which status also could be a consequence of the fast depletion of ${ }^{\circ} \mathrm{O}_{2}{ }^{-}$through its reaction with $\mathrm{NO}$, which is 3 times faster than the SOD-catalyzed reduction of ${ }^{\bullet} \mathrm{O}_{2}{ }^{-}$(Walsh, 1997).

Or study has also demonstrated that the intestine possesses several defense mechanisms in a segment-specific manner: maintains high concentrations of the antioxidant GSH and upregulates the expressions of hos and $m t$ s so as to preserve cellular integrity.

GSH is present in high concentrations in the tissues and participates in the cellular defense by scavenging ROS (Nicotera and Orrenius, 1986; Flechner et al., 1990). Our study has revealed a marked increase in GSH level in the duodenal tissues, but not in the colon, in diabetic rats. High GSH levels protect cellular proteins against oxidation through the GSH redox cycle, and also directly detoxify ROS induced by exposure to STZ (Raza et al., 2000).

Besides the GSH system, the MTs also play a noteworthy role in the maintenance of the physiological thiol/redox balance. The MTs may serve as potent antioxidants preventing diabetic complications through the suppression of diabetic oxidative damage (Dabrowiak, 2009). Our study revealed the accumulation of a huge amount of $m t-2$ mRNA in the diabetic duodenum. The expression of $m t-1$ was induced to about the same level in the diabetic duodenum and colon. In the colon, this 7-fold elevation in $m t-1 \mathrm{mRNA}$ level is one of the few positive signs of an active antioxidant defense. It has been documented that $\mathrm{Zn}$-induced $m t$ synthesis in rat pancreas prevented STZ-induced diabetes (Yang and Cherian, 1994). Elevated levels of MTs in the liver and kidney of diabetic rats have also been reported (Craft and Failla, 1983; Failla and Kiser, 1981; Uriu Hare et al., 1988), and overexpressed $m t$ in the mouse heart significantly prevented diabetes-induced cardiomyopathy (Cai and Kang, 2001; Kang and Cai, 2001).

We also demonstrated gut segment-specific changes in the expression of the HOs during diabetes. A number of in vivo and in vitro studies have indicated the induction of the HO system in response to a wide array of oxidative and cellular stresses (Applegate et al., 1991; Nath, 1994; Vile et al., 1994; Otterbein et al., 1995). HO-1 and HO-2 share similar physical and kinetic properties, but have different physiological roles and tissue distributions (Maines, 2005). In our system, hyperglycemia induced ho-1 expression in the duodenum, while in the colon increased amounts of ho-2 mRNA and HO-2 protein were detected. Unlike HO-1, which lacks 

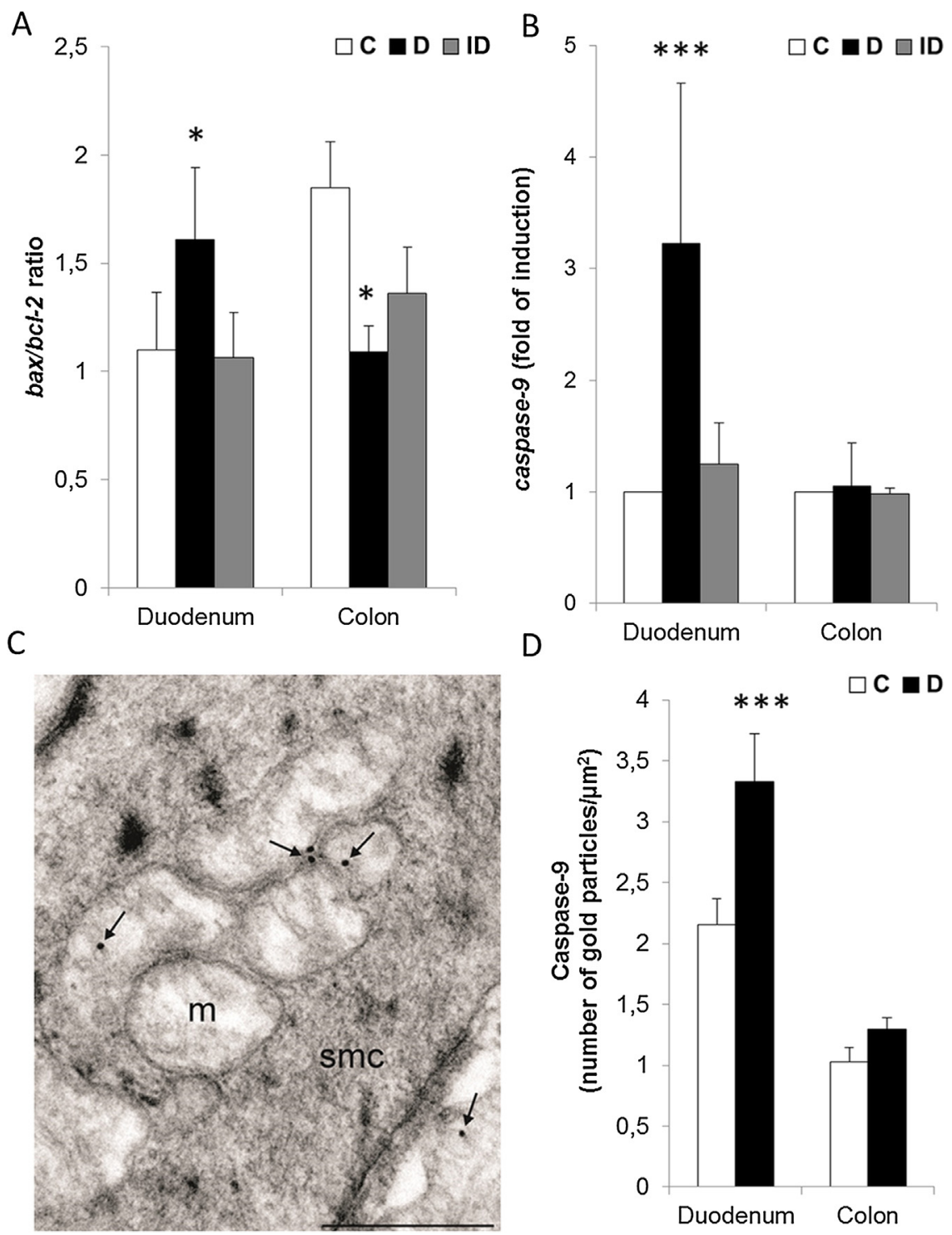

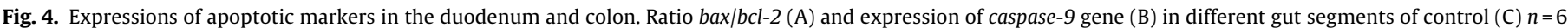

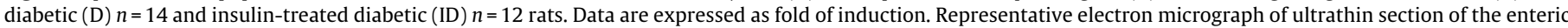

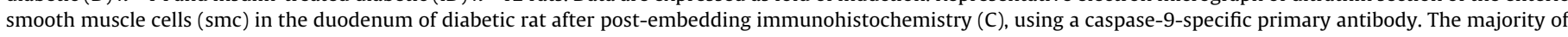

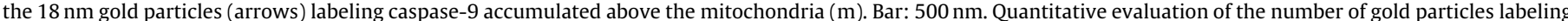
caspase-9 (D). All values are presented as means \pm S.D. ${ }^{*} p<0.05,{ }^{* *} p<0.01,{ }^{* * *} p<0.001$ (relative to controls).

cysteine residues, HO-2 contains three Cys-Pro signature motifs, known as heme regulatory motifs (HRMs). It has been proposed (Ragsdale and Yi, 2011) that the HRMs act as a "molecular rheostat" that responds to the intracellular redox potential, controlling the HO-2 activity. The level of HO-2 protein increased 11 -fold, and the activity could be further enhanced by free radicals via the CysPro signature motifs. The release of Fe ion during heme degradation before their sequestration by ferritin may make them available for the catalysis of harmful oxidation reactions (Rouault, 2009).

HO overexpression results in an anti-apoptotic phenotype associated with an increased expression of $b c l-2$ in diabetic rats (Cao et al., 2008). The survival function of bcl-2 depends on the extent of binding to proteins such as Bax that seem to antagonize bcl2 activity (Ashkenazi and Dixit, 1998; Kroemer, 1997). Our study has presented evidence of the gut region-specific expression of bcl-2, bax and caspase-9 the key elements of apoptotic pathways (Thornberry and Lazebnik, 1998). In the duodenal tissues of the diabetic rats, the level of bax expression was increased, resulting in major changes in the ratio $b a x / b c l-2$ mRNA. These changes, along with an increased level of caspase- 9 , an initiator caspase in the apoptosis pathway, indicate an enhanced pro-apoptotic environment, triggering the event of programmed cell death in the duodenum. In the diabetic colon the ratio $b a x / b c l-2$ is lowered as a consequence of upregulation of the $b c l-2$ expression. The observed increase in $b c l-2$ expression could possibly be attributed to the highly elevated HO-2 level.

All of these data suggest that the colon is more vulnerable than the duodenum to oxidative stress. The fact that the antioxidant protection is more efficient in the proximal intestinal sections than in the distal sections may be a consequence of the positional and functional differences (Blázovics et al., 2004). Earlier findings supported this (Sanders et al., 2004): the colon generates more endogenous ROS than does the small intestine, and this basic pro-oxidant environment of the colon may lead to its inability to handle oxidative stress as effectively as the small intestine. A recent study on intestinal bacterial populations in T1D likewise emphasized regionality along the GI tract; T1D affected the composition of the microbiota in a gut region-specific manner: the composition 


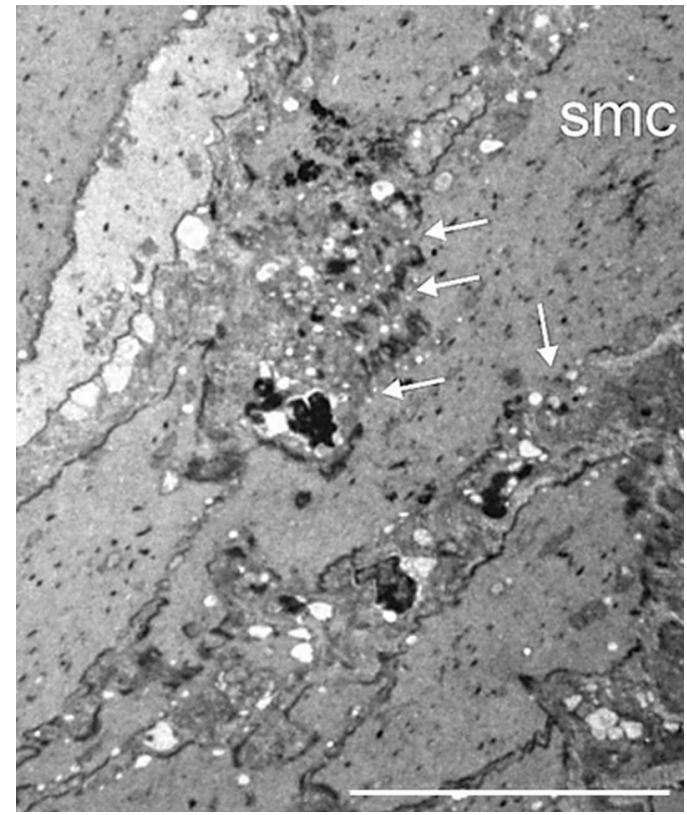

Fig. 5. Necrotic hallmark in diabetic rats. Representative electron micrograph of an ultrathin section on the colon of a diabetic rat. Smooth muscle cell (smc) with local membrane injuries and leaky cytoplasm (arrows) were frequently seen. Bar: $10 \mu \mathrm{m}$.

of the duodenal microbiota did not indicate the development of a pathological enteric microenvironment. In the diabetic colon however, the increased level of the Gram-negative Klebsiella could be associated with severe intestinal inflammation (Wirth et al., 2014).

\section{Conflict of interest statement}

The authors declare that there are no conflicts of interest.

\section{References}

Abraham NG, Cao J, Sacerdoti D, Li X, Drummond G. Heme oxygenase: the key to renal function regulation. Am J Physiol 2009;297:1137-42.

Applegate LA, Luscher P, Tyrrell RM. Induction of heme oxygenase: a general response to oxidant stress in cultured mammalian cells. Cancer Res 1991:51:974-8.

Ashkenazi A, Dixit VM. Death receptors: signaling and modulation. Science 1998;281:1305-8

Beers RF, Sizer IW. Catalase assay with special reference to manometric methods. Science 1953;117:710-2.

Bergamini CM, Gambetti S, Dondi A, Cervellati C. Oxygen, reactive oxygen species and tissue damage. Curr Pharm Des 2004;10:1611-26.

Blázovics A, Szentmihályi K, Fehér E. Alterations of redox-homeostasis in bowel parts. Z Gastroenterol 2004:42-9

Bódi N, Battonyai I, Talapka P, Hermesz E, Jancsó Zs, Katarova Z, et al. Diabetesrelated structural, molecular and functional alterations in capillaries supplying the myenteric plexus in the gut of the streptozotocin induced diabetic rats. Microcirculation 2012;19:316-26.

Cai L. Metallothionein as an adaptive protein prevents diabetes and its toxicity nonlinearity. Biol Toxicol Med 2004:2:89-103.

Cai L, Kang YJ. Metallothionein prevents diabetic cardiomyopathy. Toxicol Sci 2001;60:13.

Cao J, Drummond G, Inoue K, Sodhi K, Li XY, Omura S. Upregulation of heme oxygenase-1 combined with increased adiponectin lowers blood pressure in diabetic spontaneously hypertensive rats through a reduction in endothelial cell dysfunction, apoptosis and oxidative stress. Int J Mol Sci 2008;9:2388-406.

Craft NE, Failla ML. Zinc, iron, and copper absorption in the streptozotocin-diabetic rat. Am J Physiol 1983;244:E122-8.

Metallo-drugs and their action. In: Metals in medicine. 1st ed. Chicheste, UK: Wiley \& Sons; 2009. p. 49-72.

Failla ML, Kiser RA. Altered tissue content and cytosol distribution of trace metals in experimental diabetes. J Nutr 1981;11:1900-9.

Flechner I, Maruta K, Burkart V, Kawai K, Kolb H, Kiesel U. Effects of radical scavengers on the development of experimental diabetes. Diabetes Res 1990;13:67-73.
Gibbons SJ, Farrugia G. The role of carbon monoxide in the gastrointestinal tract. J Physiol 2004;556:325-36.

Huie RE, Padmaja S. The reaction of NO and superoxide. Free Radic Res Commun 1993:18:195-9

Inoue K, Takahashi T, Uehara K, Shimuzu H, Ido K, Morimatsu H, et al. Protective role of heme oxygenase 1 in the intestinal tissue injury in hemorrhagic shock in rats. Shock 2008;29:252-61.

Islam MS, Loots du T. Diabetes, metallothionein, and zinc interactions: a review. Biofactors 2007;29:203-12.

Izbéki F, Wittman T, Rosztóczy A, Linke N, Bódi N, Fekete E, et al. Immediate insulin treatment prevents gut motility alterations and loss of nitrergic neurons in the ileum and colon of rats with streptozotocin-induced diabetes. Diabetes Res Clin Pract 2008;80:192-8.

Kanduc D, Mittelman A, Serpico R, Sinigaglia E, Sinha AA, Natale C, et al. Cell death: apoptosis versus necrosis. Int J Oncol 2002;21:165-70.

Kang YJ, Cai L. Metallothionein suppression of diabetic cardiomyopathy by inhibition of hyperglycemia induced oxidative stress. Free Radic Biol Med 2001;31:S33.

Kroemer $\mathrm{G}$. The proto-oncogene $\mathrm{Bcl}-2$ and its role in regulating apoptosis. Nat Med 1997;3:614-20.

Kruidenier L, Kuiper I, Van Duijn W, Mieremet-Ooms MA, van Hogezand RA, Lamers $\mathrm{CB}$, et al. Imbalanced secondary mucosal antioxidant response in inflammatory bowel disease. J Pathol 2003;201:17-27.

Livak KJ, Schmittgen TD. Analysis of relative gene expression data using realtime quantitative PCR and the 2-[delta][delta]CT method. Methods 2001;25:402-8.

Lowry OH, Rosebrough NJ, Farr AL, Randall RJ. Protein measurement with the Folin phenol reagent. J Biol Chem 1951;193:265.

Maines MD. The heme oxygenase system: a regulator of second messenger gases Ann Rev Pharmacol 1997;37:517-54.

Maines MD. The heme oxygenase system: update 2005. Antioxid Redox Signal 2005; 7:1761-6.

Misra HP, Fridovich I. The role of superoxide anion in the autoxidation of epinephrine and a simple assay for superoxide dismutase. J Biol Chem 1972:247:3170-5.

Nath KA. The functional significance of induction of heme oxygenase by oxidant stress. J Lab Clin Med 1994;123:461-3.

Nicotera P, Orrenius S. Role of thiols in protection against biological reactive intermediates. Adv Exp Med Biol 1986;197:41-51.

Otterbein L, Sylvester SL, Choi AM. Hemoglobin provides protection against lethal endotoxemia in rats: the role of heme oxygenase-1. Am J Respir Cell Mol Biol 1995;13:595-601.

Pacher P, Beckman JS, Liaudet L. Nitric oxide and peroxynitrite in health and disease. Physiol Rev 2007;87:315-424.

Proskuryakov SY, Konoplyannikov AG, Gabai VL. Necrosis: a specific form of programmed cell death. Exp Cell Res 2003;283:1-16.

Rachmilewitz D, Stamler JS, Karmeli F, Mullins ME, Singel DJ, Loscalzo J, et al Peroxynitrite-induced rat colitis - a new model of colonic inflammation. Gastroenterology 1993;105:1681-8.

Ragsdale SW, Yi L. Thiol/disulfide redox switches in the regulation of heme binding to proteins. Antioxid Redox Signal 2011;14:1039-47.

Raza H, Ahmed I, John A, Sharma AK. Modulation of xenobiotic metabolism and oxidative stress in chronic streptozotocin-induced diabetic rats fed with Momordica charantia fruit extract. J Biochem Mol Toxicol 2000;14:131-9.

Rouault TA. Cell biology. An ancient gauge for iron. Science 2009;326:676-7.

Sanders LM, Henderson CE, Hong MY, Barhoumi R, Burghardt RC, Carroll RJ, et al Pro-oxidant environment of the colon compared to the small intestine may contribute to greater cancer susceptibility. Cancer Lett 2004;208:155-61.

Sedlak J, Lindsay RH. Estimation of total, protein-bound, and nonprotein sulfhydryl groups in tissue with Ellman's reagent. Anal Biochem 1968;25:192-205.

Thirumoorthy N, Sunder AS, Kumar KTM, Kumar MS, Ganesh GNK, Chatterjee M. A review of metallothionein isoforms and their role in pathophysiology. World J Surg Oncol 2011:9:54

Thornberry NA, Lazebnik Y. Caspases: enemies within. Science 1998;281:1312-6.

Uriu Hare JY, Stem JS, Keen CL. The effect of diabetes on the molecular localization of maternal and fetal zinc and copper metalloprotein in the rat. Biol Trace Elem Res 1988:18:71-9.

Vile GF, Basu-Modak S, Waltner C, Tyrrell RM. Heme oxygenase 1 mediates an adaptive response to oxidative stress in human skin fibroblasts. Proc Natl Acad Sci U S A 1994:91:2607-10.

Walsh SW. The role of oxidative stress and antioxidants in preeclampsia. Contemporary OB/GYN 1997;42:113-24.

Wang W, Ballatori N. Endogenous glutathione conjugates: occurrence and biologica functions. Pharmacol Rev 1998;50:335-56.

Wirth R, Bódi N, Maróti G, Bagyánszki M, Talapka P, Fekete E, et al. Regionally distinct alterations in the composition of the gut microbiota in rats with streptozotocininduced diabetes. PLOS ONE 2014:9:e110440.

Wolff SP. Diabetes mellitus and free radicals. Br Med Bull 1993;49:642-52.

Wolosin JD, Edelman SV. Diabetes and the gastrointestinal tract. Clin Diabetes 2000;18(4):148-51.

Yang J, Cherian MG. Protective effects of metallothionein on streptozotocin-induced diabetes in rats. Life Sci 1994;55:43-51.

Zhao J, Sha H, Zhou S, Tong X, Zhuang FY, Gregersen H. Remodelling of zero-stress state of small intestine in streptozotocin-induced diabetic rats. Effect of gliclazide. Dig Liver Dis 2002;34:707-16. 